DOI: $10.2478 / \mathrm{adms}-2014-0022$

\author{
A. Kausar ${ }^{\text {a, }}$, W. Ullah ${ }^{\text {a,b }}$, B. Muhammad ${ }^{\text {b }}$, M. Siddiq ${ }^{\text {c }}$ \\ ${ }^{a}$ Nanosciences and Catalysis Division, National Centre For Physics, Quaid-i-Azam University \\ Campus, 44000, Islamabad, Pakistan. \\ ${ }^{b}$ Department of Chemistry, Hazara University, Pakistan. \\ ${ }^{c}$ Department of Chemistry, Quaid-i-Azam University, Islamabad, Pakistan \\ *asheesgreat@yahoo.com
}

\title{
NOVEL MECHANICALLY STABLE, HEAT RESISTANT AND NON- FLAMMABLE FUNCTIONALIZED POLYSTYRENE/EXPANDED GRAPHITE NANOCOMPOSITES
}

\begin{abstract}
This study examined effect of inclusion of expanded graphite (Exp-G) on morphology, thermal, mechanical and flame retardant properties of PS, nitro-substituted polystyrene (N-PS) and amino-functional polystyrene (A-PS). FESEM showed exfoliated sheet morphology due to intercalation of N-PS and A-PS in expanded galleries. Tensile strength of A-PS materials (31.5-56.9 MPa) was higher than PS and N-PS. $10 \%$ weight loss of A-PS nanocomposites $\left(482-518{ }^{\circ} \mathrm{C}\right)$ was higher relative to pristine polymer and other nanocomposites. Cone calorimetry results revealed that there was lowering in PHHR of A-PS nanocomposites with $0.5 \mathrm{wt} . \%$ filler $\left(428 \mathrm{~kW} / \mathrm{m}^{2}\right)$, while PS nanocomposites showed PHHR of $443 \mathrm{~kW} / \mathrm{m}^{2}$.
\end{abstract}

Key words: Functional polystyrene; expanded graphite; dispersion; tensile strength; cone calorimetry

\section{INTRODUCTION}

Preparation and properties of polymer/graphite composites has been focused by the researchers in recent decades [1-3]. Graphite is naturally abundant allotrope of carbon which is made almost entirely of carbon layers. In the layers, carbon atoms are bounded by Van der Waals forces and the absolute separation of graphite layers is difficult due to higher crystal lattice energy $[4,5]$. Various methods have been explored for the preparation of hybrids with optimal physical properties and homogeneous dispersion of graphite particles in polymer matrix. In material science, various approaches for the fabrication of polymer/graphite composites have been developed and applied. The common methods include polymer blending with graphite or polymers intercalation into interlayer spacing of graphite [6-9]. Nano-dispersion of expanded graphite in various polymeric matrices such as poly(methyl methacrylate), polystyrene, and poly(vinyl chloride) using in-situ polymerization has been reported $[10,11]$. The main aim of 
these techniques is to attain uniform dispersion of graphite in continuous polymer matrix. Generally, it is difficult to achieve fine dispersion due to incompatibility of polymer and graphite. Therefore, it is essential to enhance the compatibility between nano-filler and polymer. Conventional polymer/graphite composites have been known to exhibit reduce physical properties due to poor dispersion ensuing deprived mechanical properties. Poor dispersion of filler may result in the aggregate formation owing to inadequate intercalation of macromolecules. The aggregates may not be able to reach closed cavities inside the expanded graphite. During processing, the graphite sheets around cavities tend to overlap each other and form accumulated mass. Polystyrene (PS) is a widely used polymer because of its good chemical resistance, low density, low cost, and ease of processing. However, high flammability and severe dripping during combustion greatly limit its application in buildings, transportation, and electrical appliances. In recent years, the development of halogen-free flame-retardant polymeric materials has been focused [12-14]. Traditional flame-retardant additives containing halogen elements are restricted nowadays and replaced by halogen-free counterparts such as phosphorus, metal hydroxides, nitrogen compounds, etc. Recently, carbon additives and nano-additives such as expanded graphite, graphite oxide, graphene, and carbon nanotubes are used in various polymeric systems to improve thermal and flame-retardant properties [15-19]. In addition, these nano-additives are important for improving the mechanical properties of original polymeric systems. Consequently, the previous research regarding the addition of graphite or functional graphite filler in polymers has focused the improvement of thermal stability, melt flow index, and non-flammability properties $[20,21]$. The addition of graphite filler into polystyrene using melt blending technique is also the subject of research interest [22]. Though, the synergetic improvement of the thermal, non-flammable and tensile properties of polymer/graphite nanocomposites have been less explored. In this work, polystyrene have been modified into nitro-substituted polystyrene (N-PS) and amino-functional polystyrene (A-PS). Afterwards, the expanded graphite was prepared and reinforced in pure PS, N-PS and A-PS. Three series of polystyrene/expanded graphite nanocomposite were prepared using solution blending technique to achieve uniform dispersion of nano-sheets in the matrix. The structure, morphology, mechanical properties, thermal stability and flame retardancy of the nanocomposites were studied using appropriate techniques.

\section{EXPERIMENTAL}

\section{Materials}

Polystyrene (average $\mathrm{M}_{\mathrm{w}} \sim 350,000$, average $\mathrm{M}_{\mathrm{n}} \sim 170,000$ ), polyethylene glycol (average $\mathrm{M}_{\mathrm{w}}$ $\sim 8,000$ ), graphite (fine powder), anhydrous tin(II)chloride (99 \%) was procured from Aldrich and used as received. Sodium hydroxide $(\mathrm{NaOH}, 98 \%)$, tetrahydrofuran (THF, $99 \%$ ), methanol (99\%), hydrochloric acid $(\mathrm{HCl}, 99 \%)$, nitric acid $\left(\mathrm{HNO}_{3}, 65 \%\right)$ and sulfuric acid $\left(\mathrm{H}_{2} \mathrm{SO}_{4}, 98 \%\right)$ were supplied by Merck.

\section{Instrumentation}

Infrared (IR) spectra were recorded using Fourier transform infrared (FTIR) Spectrometer, Model No. FTSW 300 MX, manufactured by BIO-RAD, California, USA ( $4 \mathrm{~cm}^{-1}$ resolution). Field Emission Scanning Electron Microscopy (FE-SEM) of freeze fractured samples was performed using JSM5910, JEOL Japan. Thermal stability was verified by METTLER TOLEDO 
TGA/SDTA 851 (California, USA) thermo gravimetric analyzer using $\mathrm{Al}_{2} \mathrm{O}_{3}$ crucible at a heating rate of $10{ }^{\circ} \mathrm{C} / \mathrm{min}$. Stress-strain behavior of the samples were studied using Testomeric materials testing machine M500-30CT. Test specimens were employed in the form of strips (lwh $40 \times 2 \times 7$ $\pm 0.05 \mathrm{~mm}^{3}$ ) according to ASTM D638 standard method. The crosshead speed was $2 \mathrm{~mm} / \mathrm{min}$ at room temperature. The data given are the average of three measurements. The combustion properties of pristine polymers and nanocomposites were calculated using cone calorimetry. Samples having dimensions $100 \times 100 \times 5 \mathrm{~mm}^{3}$ were exposed to a FTT 0007 cone calorimeter (FTT Company, England) under a heat flux of $50 \mathrm{~kW} / \mathrm{m}^{2}$ according to ISO-5660 standard procedure.

\section{Nitro-functionalization of polystyrene (N-PS)}

The nitro-functionalization of polystyrene involved the dissolution of $10 \mathrm{~g}$ of polystyrene in $50 \mathrm{~mL}$ of THF with constant stirring of $3 \mathrm{~h}$. Nitrating mixture $\left(70 \mathrm{~mL}\right.$ fuming $\mathrm{HNO}_{3}$ and $30 \mathrm{~mL}$ concentrated $\mathrm{H}_{2} \mathrm{SO}_{4}$ ) was added drop wise to the stock solution. The mixture was cooled to $0{ }^{\circ} \mathrm{C}$ in an ice bath for $6 \mathrm{~h}$ and then stirred at $60{ }^{\circ} \mathrm{C}$ for $6 \mathrm{~h}$. $30 \%$ solution of $\mathrm{NaOH}$ was added to neutralize the mixture. The functionalized polymer obtained was dried at $80^{\circ} \mathrm{C}$ for $24 \mathrm{~h}$.

\section{Amino-functionalization of polystyrene (A-PS)}

$5 \mathrm{~g}$ of nitro-functionalized polystyrene was dissolved in $30 \mathrm{~mL}$ THF with constant stirring for $2 \mathrm{~h}$. The reducing mixture was prepared by dissolving $60 \mathrm{~g}$ of anhydrous stannous chloride in $60 \mathrm{~mL}$ of hydrochloric acid at $60{ }^{\circ} \mathrm{C}$ until the solution become clear. The polymer solution and the reducing mixture were mixed and refluxed at $80^{\circ} \mathrm{C}$ for $8 \mathrm{~h}$. The mixture was neutralized with $30 \% \mathrm{NaOH}$. The brown color polymer was obtained and dried at $80{ }^{\circ} \mathrm{C}$ for $24 \mathrm{~h}$.

\section{Expansion of graphite (Exp-G)}

Two-necked round bottom flask was charged with $150 \mathrm{~mL}$ of the mixture of $\mathrm{HNO}_{3}$ and $\mathrm{H}_{2} \mathrm{SO}_{4}$ (1:2). $5 \mathrm{~g}$ of graphite was added to the above mixture and stirred for $12 \mathrm{~h}$ at room temperature. The mixture was neutralized with distilled water and then filtered. The powder was dried in an oven at $100{ }^{\circ} \mathrm{C}$ for $12 \mathrm{~h}$. For further expansion of the above modified graphite, the dried powder was placed in a heated muffle furnace at $500{ }^{\circ} \mathrm{C}$ for $0.5 \mathrm{~min}$. The temperature of $500{ }^{\circ} \mathrm{C}$ was found adequate for thermal exfoliation. $1 \mathrm{~g}$ of polyethylene glycol was dissolved in 30 $\mathrm{mL}$ of THF with sonication of $6 \mathrm{~h}$. After that $2 \mathrm{~g}$ of expanded graphite was added to PEG and sonicated for $8 \mathrm{~h}$. The mixture was neutralized and filtered. Finally the modified graphite was dried at $100^{\circ} \mathrm{C}$ for $12 \mathrm{~h}$ (Fig. 1) [23]. The sample designation, composition and codes used in this study are given in Table 1 .

\section{Preparation of nanocomposites from non-modified and modified polystyrene and expanded graphite}

Three series of nanocomposites (PS 1-5, N-PS 1-5 and A-PS 1-5) were prepared with exfoliated graphite. Here again, $1 \mathrm{~g}$ of polystyrene (PS, N-PS or A-PS), was dissolved in $10 \mathrm{~mL}$ of THF to prepare the stock solution with stirring of $6 \mathrm{~h}$. Expanded graphite $(0.01 \mathrm{~g}, 0.05 \mathrm{~g}, 0.1 \mathrm{~g}$, $0.3 \mathrm{~g}$ and $0.5 \mathrm{~g}$ ) was added to the stock solution and further stirred for $6 \mathrm{~h}$. Thin nanocomposite films were cast in Teflon Petri dishes. 

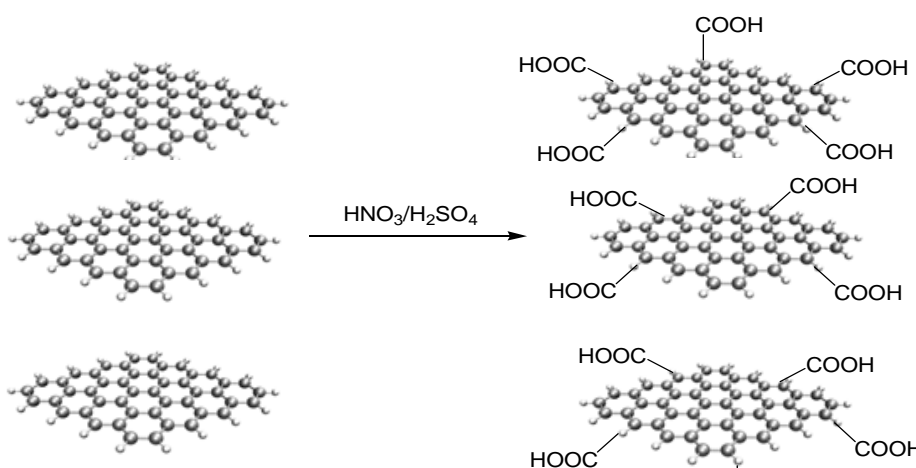

$\mathrm{HOOC} \mathrm{COOH}$
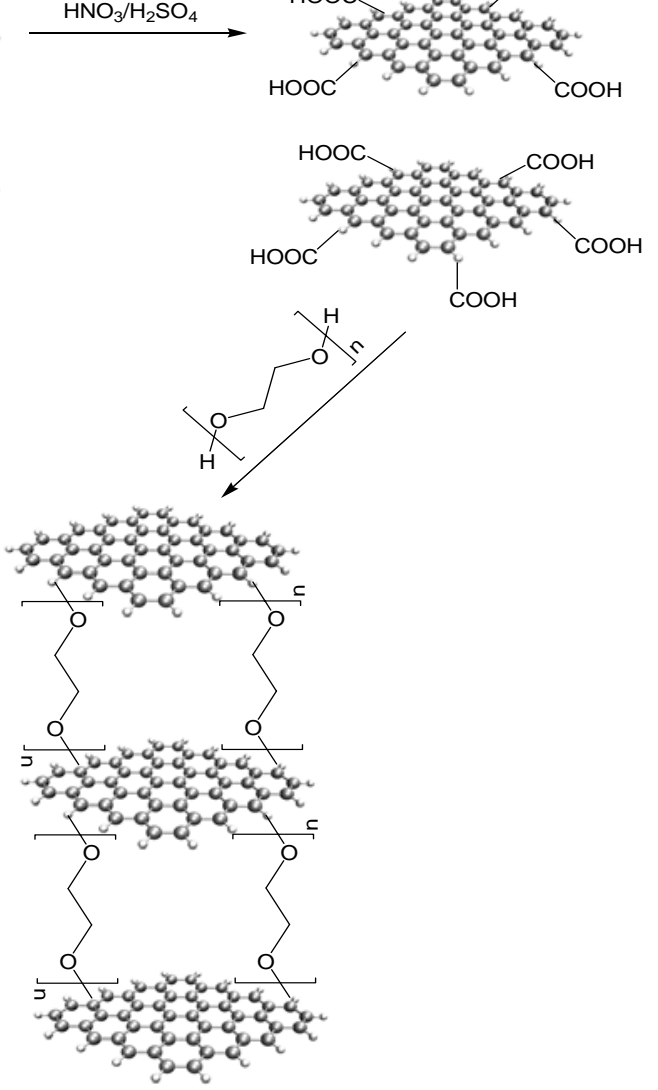

Fig. 1. Schematic illustration for the expansion of graphite using polyethylene glycol

Table 1. Sample codes and composition of the nanocomposites

\begin{tabular}{ccc}
\hline Sample Code & Matrix & $\begin{array}{c}\text { Expanded Graphite } \\
\text { (wt. \%) }\end{array}$ \\
PS 1 & Polystyrene & 0.01 \\
PS 2 & Polystyrene & 0.05 \\
PS 3 & Polystyrene & 0.1 \\
PS 4 & Polystyrene & 0.3 \\
PS 5 & Polystyrene & 0.5 \\
N-PS 1 & Nitro-functional polystyrene & 0.01 \\
N-PS 2 & Nitro-functional polystyrene & 0.05 \\
N-PS 3 & Nitro-functional polystyrene & 0.1 \\
N-PS 4 & Nitro-functional polystyrene & 0.3 \\
N-PS 5 & Nitro-functional polystyrene & 0.5 \\
A-PS 1 & Amino-functional polystyrene & 0.01 \\
A-PS 2 & Amino-functional polystyrene & 0.05 \\
A-PS 3 & Amino-functional polystyrene & 0.1 \\
A-PS 4 & Amino-functional polystyrene & 0.3 \\
A-PS 5 & Amino-functional polystyrene & 0.5 \\
\hline
\end{tabular}




\section{RESULTS AND DISCUSSION}

\section{FTIR analysis}

Fig. 2 shows the FTIR spectra of N-PS 3 and A-PS 3 nanocomposites. The spectrum of NPS 3 (Fig. 2A) displays strong vibration at 3025 and $3055 \mathrm{~cm}^{-1}$ due to aromatic $\mathrm{C}-\mathrm{H}$ character. Moreover, the aliphatic $\mathrm{C}-\mathrm{H}$ stretching vibrations at 2850 and $2921 \mathrm{~cm}^{-1}$ were present due to polystyrene structure.
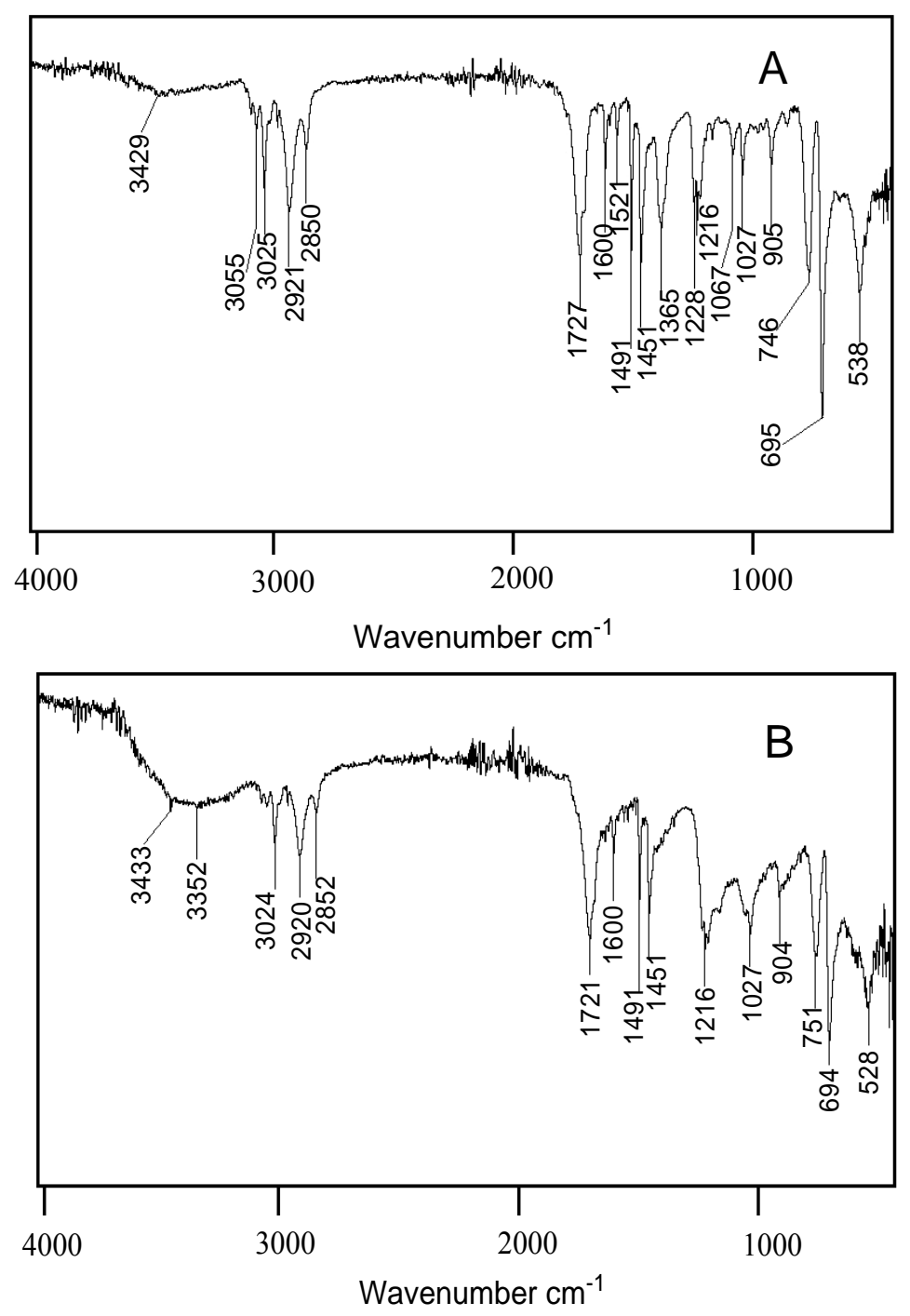

Fig. 2. FTIR spectra of (A) N-PS 3; and (B) A-PS 3 nanocomposites

The spectrum also exhibited $\mathrm{O}-\mathrm{H}$ stretching vibration at 3429 due to the expanded graphite structure using PEG. A $\mathrm{C}=\mathrm{C}$ peak $\left(1600 \mathrm{~cm}^{-1}\right)$ corresponding to the $\mathrm{sp}^{2}$ character was also appeared. The stretching vibration of $\mathrm{C}=\mathrm{O}$ carbonyl groups introduced on the surface of expanded graphite appeared at $1721 \mathrm{~cm}^{-1}$. Moreover, the asymmetric stretching vibration of $\mathrm{NO}_{2}$ appeared at $1521 \mathrm{~cm}^{-1}$ indicating the successful attachment of $\mathrm{NO}_{2}$ group to the matrix. The 
stretching vibrations at 1216 and $1365 \mathrm{~cm}^{-1}$ were considered to be appear because of $\mathrm{C}-\mathrm{O}-\mathrm{C}$ and $\mathrm{CO}-\mathrm{H}$ stretching. The $\mathrm{C}-\mathrm{H}$ out of plane bending vibrations were found at 746 and $695 \mathrm{~cm}^{-1}$ related to benzene ring. FTIR spectrum of A-PS 3 is shown in Fig. 1B. The spectrum displayed $\mathrm{O}-\mathrm{H}$ stretching vibration at 3433 due to the expanded graphite structure similar to the spectrum of N-PS 3. The N-H stretching vibration appeared at $3352 \mathrm{~cm}^{-1}$ signifying the attachment of amine group to the matrix, while $\mathrm{NO}_{2}$ peak at $1521 \mathrm{~cm}^{-1}$ was disappeared. The aromatic $\mathrm{C}-\mathrm{H}$ stretching vibration emerged at $3024 \mathrm{~cm}^{-1}$ while aliphatic $\mathrm{C}-\mathrm{H}$ stretching vibration was observed at 2852 and $2920 \mathrm{~cm}^{-1}$. The carbonyl stretch was also found at $1721 \mathrm{~cm}^{-1}$. In A-PS 3 nanocomposite, $\mathrm{C}-\mathrm{O}-\mathrm{C}$ and $\mathrm{C}-\mathrm{H}$ out of-plane benzene ring bending vibrations were also found at 1216,751 and $694 \mathrm{~cm}^{-1}$.

\section{Mechanical properties}

Table 2 presents the tensile properties of neat polystyrene, modified polystyrene, PS 1-5, NPS 1-5 and A-PS 1-5 nanocomposites. Pure polystyrene, nitro-functional and amino-functional polystyrene depicted relatively lower tensile strength of 20.3, 22.6 and 25.7 MPa compared with nanocomposite series. The tensile modulus of these materials was also studied. The tensile modulus usually measures the resistance of a material to elastic/recoverable deformation under load. A stiff material has high modulus and undergoes slight change in shape under elastic loads while a flexible material has low modulus and changes its shape considerably.

Table 2. Mechanical properties of PS, N-PS, A-PS, PS 1-5, N-PS 1-5 and A-PS 1-5 films

\begin{tabular}{lcccc}
\hline Composition & $\begin{array}{c}\text { Tensile Strength } \\
(\mathrm{MPa}) \pm 0.04\end{array}$ & $\begin{array}{c}\text { Elongation at break } \\
\pm 0.01(\%)\end{array}$ & $\begin{array}{c}\text { Tensile Modulus } \\
(\mathrm{GPa}) \pm 0.02\end{array}$ & $\begin{array}{c}\text { Toughness } \\
\left(\mathrm{Jm}^{-3}\right) \pm \\
0.05\end{array}$ \\
\hline PS & 20.3 & 0.02 & 0.7 & 0.14 \\
N-PS & 22.6 & 0.02 & 0.8 & 0.14 \\
A-PS & 25.7 & 0.02 & 0.9 & 0.15 \\
PS 1 & 25.9 & 10.8 & 1.9 & 559 \\
PS 2 & 31.3 & 9.4 & 2.7 & 622 \\
PS 3 & 36.6 & 8.8 & 3.5 & 735 \\
PS 4 & 38.9 & 7.8 & 5.3 & 844 \\
PS 5 & 40.5 & 6.7 & 6.4 & 967 \\
N-PS 1 & 29.7 & 12.3 & 3.3 & 654 \\
N-PS 2 & 37.2 & 11.7 & 5.8 & 876 \\
N-PS 3 & 43.1 & 10.2 & 7.1 & 889 \\
N-PS 4 & 49.4 & 9.8 & 7.8 & 976 \\
N-PS 5 & 52.3 & 8.2 & 8.4 & 1002 \\
A-PS 1 & 31.5 & 14.1 & 6.2 & 798 \\
A-PS 2 & 38.8 & 13.2 & 7.5 & 867 \\
A-PS 3 & 46.2 & 12.7 & 8.8 & 1011 \\
A-PS 4 & 52.8 & 11.4 & 9.7 & 1211 \\
A-PS 5 & 56.9 & 10.2 & 10.1 & 1308 \\
\hline
\end{tabular}

The tensile modulus PS, N-PS and A-PS was found to be lower 0.7, 0.8, 0.9 GPa relative to the composites. The most probable reason was that the inclusion of exfoliated graphite filler has probably increased the stiffness of material towards the applied load. On the other hand, the pristine and modified polymers without the nano-filler have relatively less rigid structure, which 
was less resistant to the applied load. The toughness is the resistance to failure or crack propagation. Toughness relates to the amount of energy absorbed in order to propagate a crack. The materials with high toughness require greater energy to maintain the crack propagation. The toughness of PS, N-PS and A-PS was found to be $0.14,0.14$ and $0.15 \mathrm{Jm}^{-3}$.

While studying the effect of expanded graphite loading on the tensile strength, the PS 1-5 was found to have lower values in tensile strength (25.9-40.5 MPa) relative to N-PS 1-5 (29.7-52.3 $\mathrm{MPa}$ ) and A-PS 1-5 (31.5-56.9 $\mathrm{MPa})$ nanocomposites. The most probable reason was the increased toughness of the N-PS and A-PS matrices after modification and hybrid formation. However, the filler loading in the matrices (PS, N-PS and A-PS) resulted in higher mechanical stability compared with the pure polymers. The tensile modulus also had increasing trend in the nanocomposites.

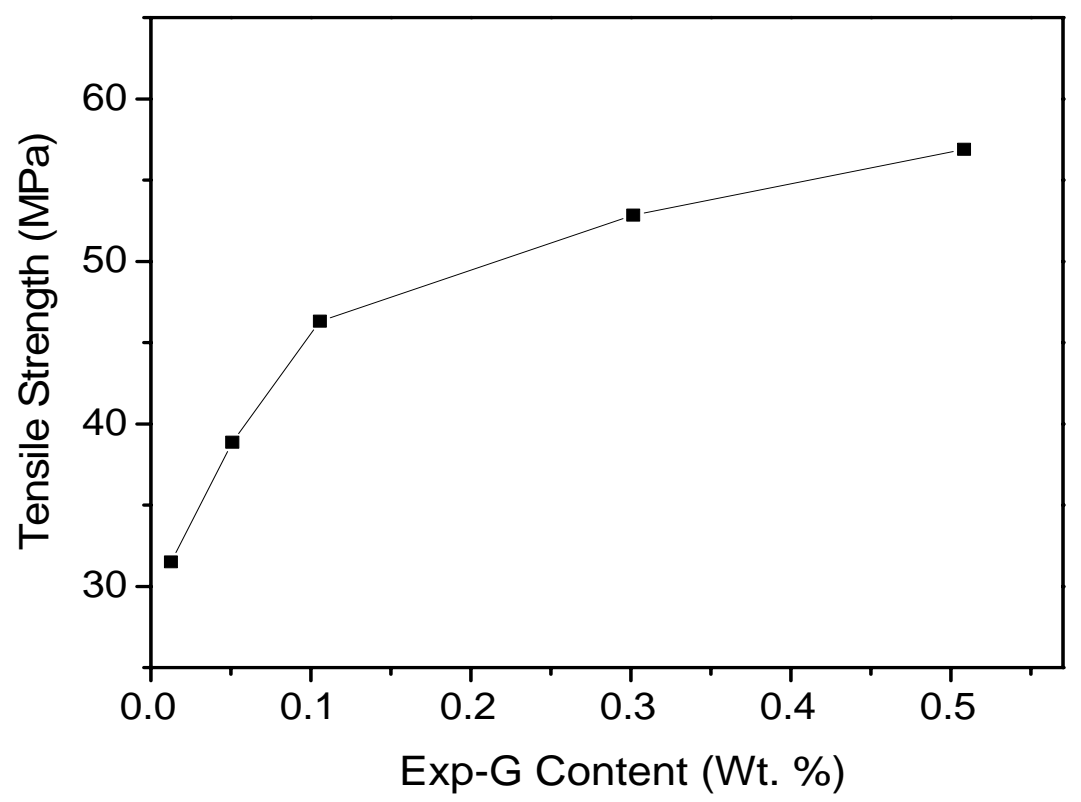

Fig. 3. Increasing trend of tensile strength vs. expanded graphite loading in APS-based nanocomposites

Here again, A-PS 1-5 showed higher values in the tensile modulus $(6.2-10.1 \mathrm{GPa})$ relative to PS 1-5 (1.9-6.4 GPa) and N-PS 1-5 (3.3-8.4 GPa) nanocomposites. The toughness of the A-PS 1-5 nanocomposite series was also found to be higher $798-1308 \mathrm{Jm}^{-3}$ relative to the PS 1-5 (559-967 $\mathrm{MPa})$ and the N-PS 1-5 (654-1002 MPa). Dependence of the tensile strength of the N-PS 1-5 nanocomposites on expanded graphite content is given in Fig. 3. In the nanocomposite series prepared, the optimal results were obtained for $0.5 \mathrm{wt}$. \% filler loading in amino-funnctionalized polystyrene matrix owing to the better intercalation of the functional polymer in expanded graphite galleries.

\section{Morphological study}

FE-SEM was performed for the samples including PS 5, N-PS 5 and A-PS 5. Fig. 4A-C shows the morphology of pure polystyrene matrix loaded with $0.05 \mathrm{wt} . \%$ expanded graphite. The surface morphology was observed to be of an encrusted structure reflecting its layered arrangement. However, the expansion of graphite sheets due to polymer intercalation was not so apparent in the micrographs because of the less interaction between the matrix and Exp-G. 
The fractured surface of 0.05 wt. \% expanded graphite loaded nitro-functional PS is given in Fig. $5 \mathrm{~A} \& \mathrm{~B}$. The morphology of the samples was observed to be of a wrinkled and folded texture showing the layered microstructure. Fig. 5C-D also displayed wrinkled and folded consistency and the layering was more prominent in the A-PS matrix. The morphology of N-PS 2 and A-PS 2 also showed that the exfoliated graphite flakes tend to organize inside the polymer matrix owing to the fine dispersion. The folded and layered morphology is usually observed for the exfoliated graphite-based nanocomposites [24].

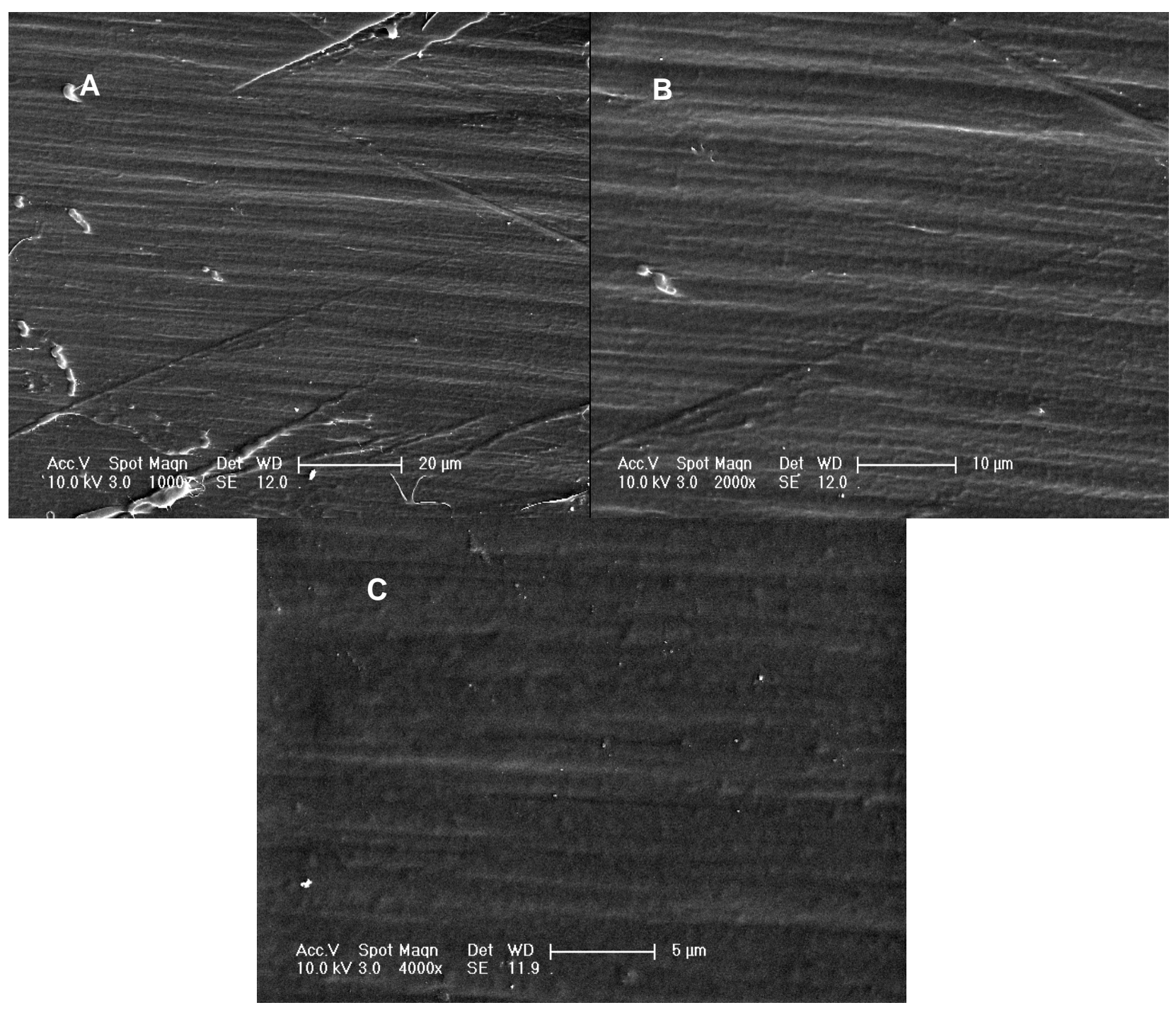

Fig. 4. FESEM micrographs of (A) PS 2 at $20 \mu \mathrm{m}$; (B) PS 2 at $10 \mu \mathrm{m}$; (C) PS 2 at $5 \mu \mathrm{m}$; 


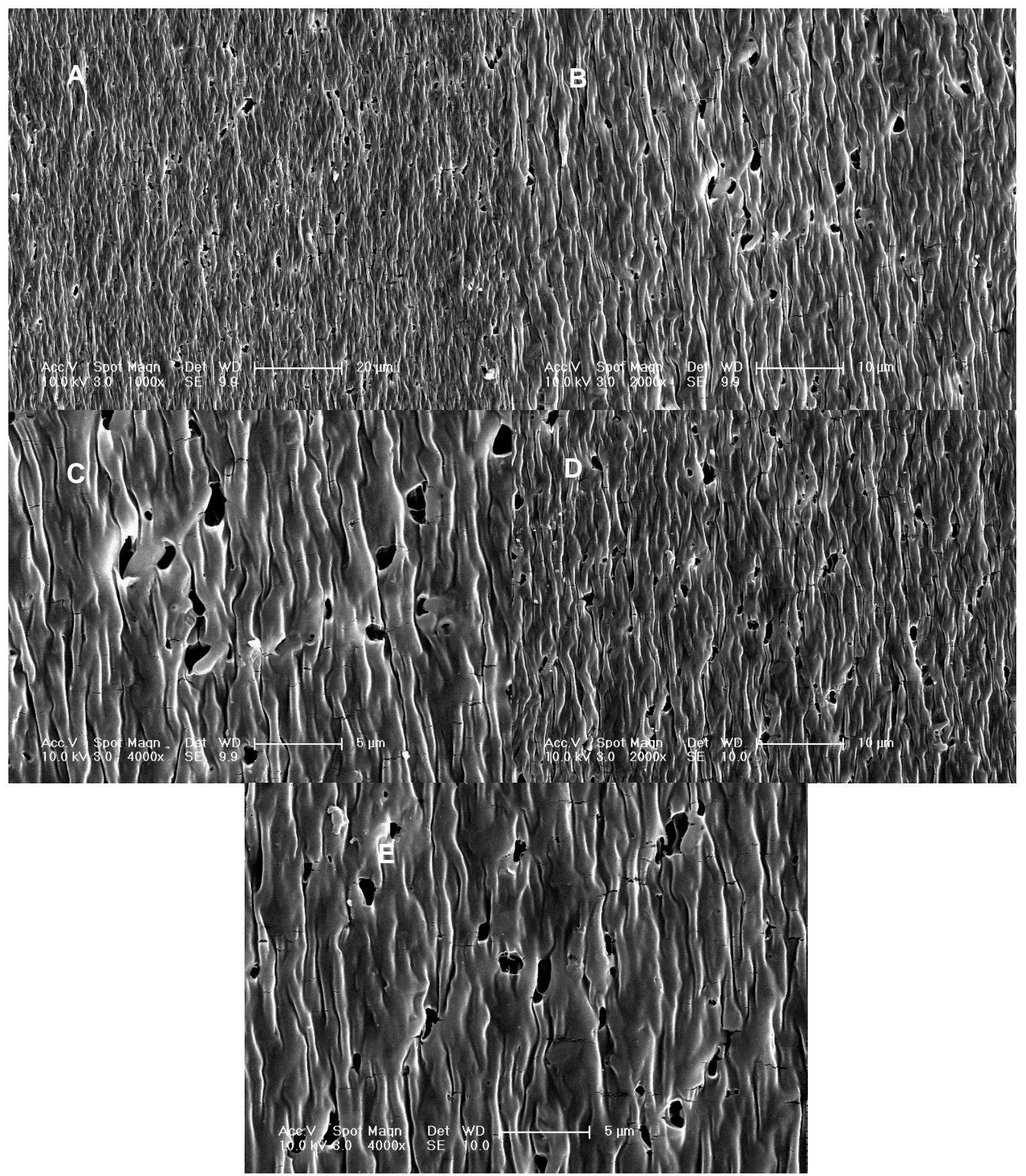

Fig. 5. FESEM micrographs of (A) N-PS 2 at $20 \mu \mathrm{m}$; (B) N-PS 2 at $10 \mu \mathrm{m}$; (C) N-PS 2 at $5 \mu \mathrm{m}$; (D) A-PS 2 at $10 \mu \mathrm{m}$; and (E) A-PS 2 at $5 \mu \mathrm{m}$

\section{Thermal stability}

The results for the PS, N-PS, A-PS, PS 1-5, N-PS 1-5 and A-PS 1-5 films are presented in Table 3. The data include the onset temperature of degradation $\left(\mathrm{T}_{0}\right)$, the temperature at which 10 $\%$ weight loss occurred $\left(\mathrm{T}_{10}\right)$, maximum weight loss temperature $\left(\mathrm{T}_{\max }\right)$ and char yield. The $\mathrm{T}_{0}$ of PS was $320^{\circ} \mathrm{C}$, while the $\mathrm{T}_{0}$ values of the N-PS and A-PS were 345 and $370{ }^{\circ} \mathrm{C}$ respectively. For 
the PS 1-5 series, the $\mathrm{T}_{0}$ was $425,431,439,446$ and $459{ }^{\circ} \mathrm{C}$ for $0.01,0.05,0.1,0.3$ and 0.5 wt. $\%$ expanded graphite respectively. The $\mathrm{T}_{10}$ of PS 1-5 nanocomposite was also found to be higher than that of neat PS and the modified matrices as $432,444,450,458$ and $465{ }^{\circ} \mathrm{C}$ for $0.01,0.05$, $0.1,0.3$ and 0.5 wt. $\%$ loading. The $\mathrm{T}_{\max }$ was $468,470,475,483$ and $492{ }^{\circ} \mathrm{C}$ for $0.01,0.05,0.1$, 0.3 and 0.5 wt. $\%$ loading respectively in this series. For the neat N-PS loaded with $0.01-0.5$ wt. $\%$ expanded filler, the $\mathrm{T}_{0}, \mathrm{~T}_{10}$ and $\mathrm{T}_{\max }$ was found to be in the range 425-459, 432-465 and 468$492{ }^{\circ} \mathrm{C}$. Among the nanocomposites, the A-PS 1-5 provided the optimal thermal stability compared with the pure PS, N-PS and A-PS and the nanocomposites. The TGA curves for A-PS 1-5 nanocomposites are presented in Fig. 6. For the A-PS 1-5 series $\mathrm{T}_{0}$ was 473, 481, 488, 492 and $501{ }^{\circ} \mathrm{C}$ for $0.01,0.05,0.1,0.3$ and $0.5 \mathrm{wt}$. \% expanded graphite respectively. The $\mathrm{T}_{10}$ of A-PS 1-5 nanocomposite was also found to be higher than that of neat PS, the modified matrices, the nitro-functional matrix and its nanocomposite. The $\mathrm{T}_{10}$ was $482,491,498,500$ and $518{ }^{\circ} \mathrm{C}$ for $0.01,0.05,0.1,0.3$ and 0.5 wt. \% loading respectively in A-PS 1-5 nanocomposite. $\mathrm{T}_{\max }$ was 510 , $517,520,529$, and $534{ }^{\circ} \mathrm{C}$ for $0.01,0.05,0.1,0.3$ and $0.5 \mathrm{wt} . \%$ loading respectively in the A-PSbased nanocomposite.

Table 3. Thermal analyses data of PS, N-PS, A-PS, PS 1-5, N-PS 1-5 and A-PS 1-5 films

\begin{tabular}{|c|c|c|c|c|}
\hline Composition & $\mathrm{T}_{0}\left({ }^{0} \mathrm{C}\right)$ & $\mathrm{T}_{10}\left({ }^{\circ} \mathrm{C}\right)$ & $\mathrm{T}_{\max }\left({ }^{0} \mathrm{C}\right)$ & $\begin{array}{c}Y_{c} \text { at } 600{ }^{\circ} \mathrm{C} \\
(\%)\end{array}$ \\
\hline PS & 320 & 373 & 396 & 12 \\
\hline N-PS & 345 & 382 & 402 & 26 \\
\hline A-PS & 370 & 385 & 415 & 29 \\
\hline PS 1 & 425 & 432 & 468 & 44 \\
\hline PS 2 & 431 & 444 & 470 & 49 \\
\hline PS 3 & 439 & 450 & 475 & 50 \\
\hline PS 4 & 446 & 458 & 483 & 52 \\
\hline PS 5 & 459 & 465 & 492 & 54 \\
\hline N-PS 1 & 437 & 441 & 481 & 45 \\
\hline N-PS 2 & 445 & 449 & 484 & 51 \\
\hline N-PS 3 & 459 & 458 & 490 & 54 \\
\hline N-PS 4 & 462 & 465 & 494 & 55 \\
\hline N-PS 5 & 469 & 478 & 499 & 56 \\
\hline A-PS 1 & 473 & 482 & 510 & 57 \\
\hline A-PS 2 & 481 & 491 & 517 & 58 \\
\hline A-PS 3 & 488 & 498 & 520 & 60 \\
\hline A-PS 4 & 492 & 500 & 529 & 61 \\
\hline A-PS 5 & 501 & 518 & 534 & 63 \\
\hline
\end{tabular}

$\mathrm{T}_{0}$ : Initial decomposition temperature

$\mathrm{T}_{10}:$ Temperature for $10 \%$ weight loss

$\mathrm{T}_{\max }:$ Maximum decomposition temperature

$\mathrm{Y}_{\mathrm{c}}$ : Char yield; weight of polymer remained 


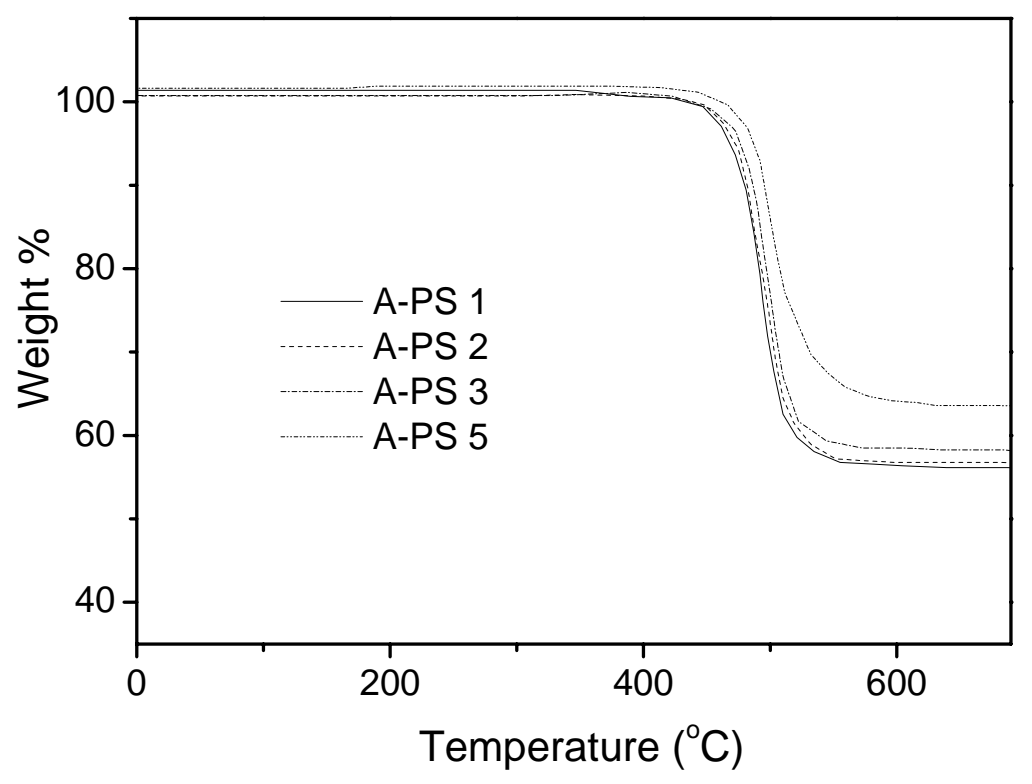

Fig. 6. Thermal degradation patterns of A-PS-based nanocomposites obtained through TGA

Above consequences have proved that the amino-modification of PS was beneficial for the enhancement of heat constancy of the nanocomposites. In the case of char residues at $600{ }^{\circ} \mathrm{C}$, the char yield of expanded graphite-based nanocomposites was increased relative to that of the neat PS, N-PS, A-PS, N-PS 1-5 and A-PS 1-5 systems. The A-PS 1-5 nanocomposites depicted higher char yield values in the range of $57-63 \%$ at $600{ }^{\circ} \mathrm{C}$. The flame retardant properties of nanocomposites can also be studied in terms of the char yields. According to literature, the higher thermal residue in the range $600-700^{\circ} \mathrm{C}$ is often related to flame resistance $[25,26]$. Moreover, the char yield up to $63 \%$ shows that the polymers have high intrinsic fire resistance i.e. thermal stability. Increasing char formation could limit the production of combustible gases; decrease the exothermicity of the pyrolysis reaction and restrict the polymer's flammability. Furthermore the addition of expanded graphite in amino-functional matrix promoted the carbonization on the polymer surface, thus, increasing the heat resistance and contributed to the higher char residues. The flame retardancy of the materials was evaluated by cone calorimetric analysis.

\section{Flame-retardant properties}

To assess the flame retardancy, the heat release rate (HRR) and the peak heat release rate (PHRR) values are important parameters. The HRR plots for polystyrene and the nanocomposites are shown in Fig. 7. It was found that the nanocomposites had significantly lower HRR than that of the virgin polymer. The PHRR values of the PS, N-PS and A-PS were found to be higher 860, 844 and $823 \mathrm{~kW} / \mathrm{m}^{2}$ respectively (Table 4). The expanded graphite-based hybrids PS 5, N-PS 5 and A-PS 5 have considerably lower PHHR values as 443, 432 and $428 \mathrm{~kW} / \mathrm{m}^{2}$. The inclusion of expanded graphite to the PS matrix decreased the heat release values. The lower PHRR was obtained for the expanded graphite incorporated in amino-functional matrix. Pure polystyrene presented a sharp HRR owing to the degradation as well as the stabilization of the char formation [27]. The reduction of HRR values in A-PS 5 nanocomposite was also accompanied by the decrease in ignition time. The expanded graphite actually served as a barrier to mass transport and somewhat insulated the underlying polymer from the ignition. 


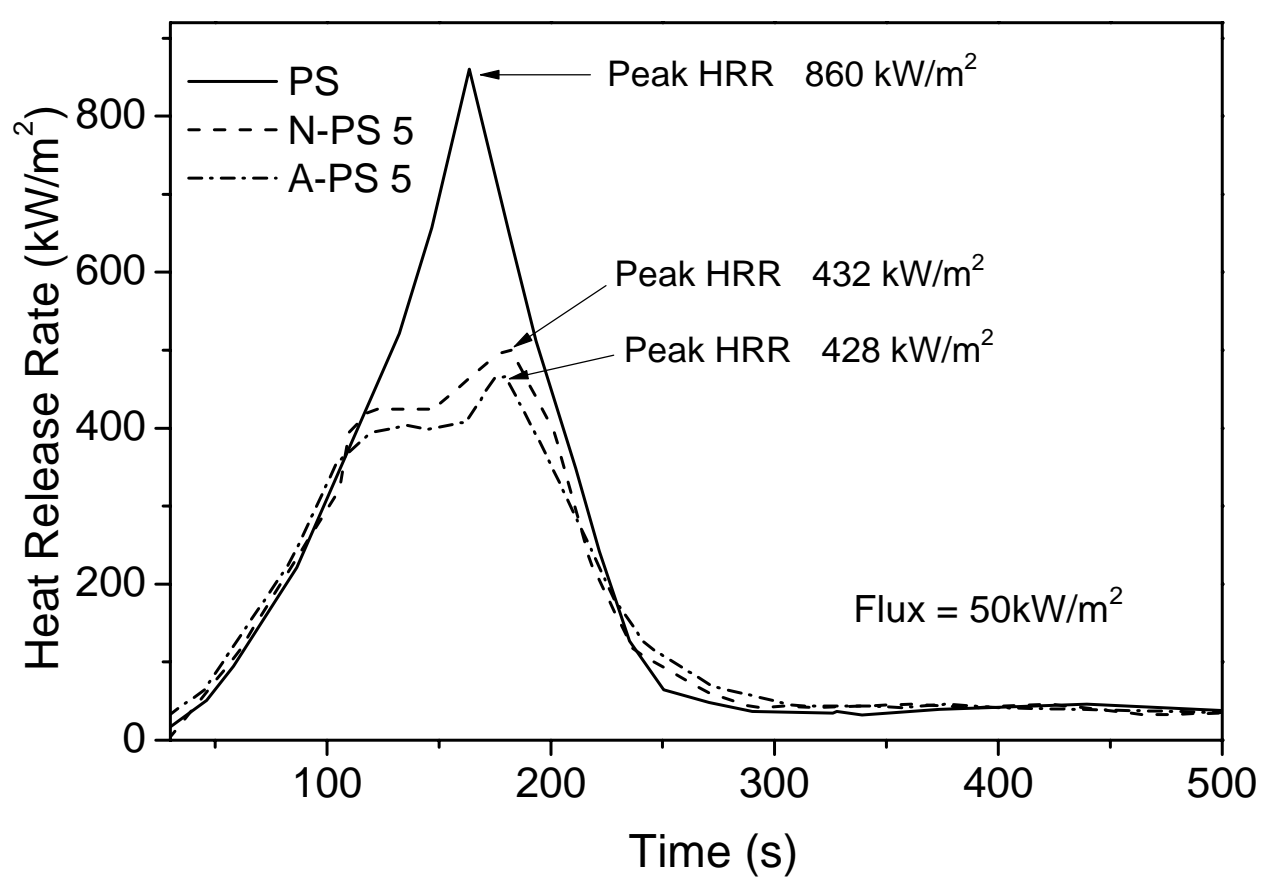

Fig. 7. Plots of heat release rate vs. burning time for PS and nanocomposites

Table 4. PHRR of pristine polymers and nanocomposites

\begin{tabular}{|c|c|}
\hline Sample & $\operatorname{PHRR}\left(\mathrm{kW} / \mathrm{m}^{2}\right)$ \\
\hline PS & 860 \\
\hline N-PS & 844 \\
\hline A-PS & 823 \\
\hline PS 5 & 443 \\
\hline N-PS 5 & 432 \\
\hline A-PS 5 & 428 \\
\hline
\end{tabular}

CONCLUSIONS

In this research effort, the expanded graphite was loaded in the neat polystyrene and functional polystyrene in different wt. \%. The structural characterization by FTIR confirmed the structure of nanocomposites. The fracture toughness and the tensile strength of the nanocomposites were found to rise with Exp-G loading. The morphology analysis showed that the expanded graphite formed well-dispersed morphology in PS, N-PS and A-PS matrices. From TGA analysis, the thermal stability of the nanocomposites was found to increase with the increasing graphite content. The cone calorimetry results suggested the reduction in PHRR values with increasing filler content. The optimal flammability was obtained with the $0.5 \mathrm{wt} \%$ expanded graphite, in this case the reduction in the peak PHRR was almost $50 \%$ as compared to neat PS. 


\section{REFERENCES}

1. Pluta M., Alexandre M., Blacher S., Dubois P., Jerome R.: Metallocene-catalyzed polymerization of ethylene in the presence of graphite, Structure and electrical properties of the composites, Polymer 42 (2001) 9293-9300.

2. Celzard A., Krzesinska M., Begin D., Mareche J. F., Puricelli S., Furdin G.: Preparation, electrical and elastic properties of new anisotropic expanded graphite-based composites. Carbon 40 (2002) 557-566.

3. Zheng W. G., Wong S. C., Sue H. J.: Transport behavior of PMMA/expanded graphite nanocomposites. Polymer 43 (2002) 6767-6773.

4. Chen G. H., Wu D. J., Weng W. G., Yan W. L.: Preparation of Polystylene-Graphite Conducting Nanocomposites via Intercalation Polymerization. Journal of Applied Polymer Science 82 (2001) 2506-2513.

5. Uhl F. M., Wilkie C. A.: Polystyrene/graphite nanocomposites: effect on thermal stability. Polymer Degradation and Stability 76 (2002) 111-122.

6. Liu P. G., Gong K. C.: Synthesis and characterization of polyaniline intercalated graphite oxide composite. Acta Polymerica Sinica 4 (2000) 492-495.

7. Pan Y. X., Yu Z. Z., Ou Y. C., Feng Y. P.: Preparation and properties of nylon 6/graphite nanocomposite. Acta Polymerica Sinica 1 (2001) 42-47.

8. Xiao P., Xiao M., Liu P. G., Gong K. C.: Direct synthesis of a polyaniline-intercalated graphite oxide nanocomposite. Carbon 38 (2000) 626-628.

9. Chen G. H., Wu D. J., Weng W. G., Yan W. L.: Dispersion of graphite nanosheets in a polymer matrix and the conducting property of the nanocomposites. Polymer Engineering and Science 41 (2001) 2148-2154.

10. Panwar V., Kang B., Park J. O., Park S., Mehta R. M.: Study of dielectric properties of styreneacryloni- trile graphite sheets composites in low and high frequency region. European Polymer Journal 45 (2009) 1777-1784.

11. Stankovich S., Dikin D. A., Piner R. D., Kohlhaas K. A., Kleinhammes A., Jia Y., Wu Y., Nguyen S. T., Ruoff R. S.: Synthesis of graphene-based nanosheets via chemical reduction of exfoliated graphite oxide. Carbon, 45 (2007) 1558-1565.

12. Sudhakara P., Kannan P., Obireddy K., Rajulu A. V.: Flame retardant diglycidylphenylphosphate and diglycidyl ether of bisphenol-A resins containing Borassus fruit fiber composites. Journal of Materials Science 46 (2011) 5176-5183.

13. D. Konnicke, A. Kuhn, T. Mahrholz, M. Sinapius. 'Polymer nanocomposites based on epoxy resin and ATH as a new flame retardant for CFRP: preparation and thermal characterization. Journal of Materials Science 46 (2011) 7046-7055.

14. He Q. L., Song L., Hu Y., Zhou S.: Synergistic effects of polyhedral oligomeric silsesquioxane (POSS) and oligomeric bisphenyl A bis(diphenyl phosphate) (BDP) on thermal and flame retardant properties of polycarbonate. Journal of Materials Science 44 (2009) 1308-1316.

15. Murariu M., Dechief A. L., Bonnaud L., Paint Y., Gallos A., Fontaine G., Bourbigot S., Dubois P.: The production and properties of polylactide composites filled with expanded graphite. Polymer Degradation and Stability 95 (2010) 889-900. 
16. Bian X. C., Tang J. H., Li Z. M., Lu Z. Y., Lu A.: Dependence of flame-retardant properties on density of expandable graphite filled rigid polyurethane foam. Journal of Applied Polymer Science 104 (2007) 3347-3355.

17. S. Peeterbroeck, F. Laoutid, J. M. Taulemesse, F. Monteverde, J. Lopez-Cuesta, J. B. Nagy, M. Alexandre, P. Dubois. Mechanical properties and flame-retardant behavior of ethylene vinyl acetate/high-density polyethylene coated carbon nanotube nanocomposites. Advanced Functional Materials 17 (2007) 2787-2791.

18. Isitman N. A., Kaynak C.: Nanoclay and carbon nanotubes as potential synergists of an organophosphorus flame-retardant in poly(methyl methacrylate). Polymer Degradation and Stability 95 (2010) 1523-1532.

19. Lee Y. C. R., Kim S. C., Lee H., Jeong H. M., Raghu A. V., Reddy K. R., Kim B. K.: Graphite oxides as effective fire retardants of epoxy resin. Macromolecular Research 19 (2011) 66-71.

20. Shi Y., Li L. J.: Chemically modified graphene: flame retardant or fuel for combustion. Journal of Materials Chemistry 21 (2011) 3277-3279.

21. Wang X., Song L., Yang H., Lu H., Hu Y.: Synergistic effect of graphene on antidripping and fire resistance of intumescent flame retardant poly(butylene succinate) composites. Industrial \& Engineering Chemistry Research 50 (2011) 5376-5383.

22. Bao C. L., Guo Y., Yuan B., Hu Y., Song L.: Functionalized graphene oxide for fire safety applications of polymers: a combination of condensed phase flame retardant strategies. Journal of Materials Chemistry 22 (2012) 23057-23063.

23. Wen-Pin W., Cai-Yuan P.: Preparation and characterization of polystyrene/graphite composite prepared by cationic grafting polymerization. Polymer 45 (2004) 3987-3995.

24. Guo-Hua C., Da-Jun W., Wen-Gui W., Bin H., Wen-li Y.: Preparation of polystyrene-graphite conducting nanocomposites via intercalation polymerization. Polymer International 50 (2001) 980985.

25. Kausar A., Zulfiqar S., Sarwar M. I.: An investigation on new high performance Schiff base polyurethanes. High Performance Polymers 24 (2012) 125-134.

26. Kausar A., Zulfiqar S., Sarwar M. I.: High performance segmented polyurethanes derived from a new aromatic diisocyanate and polyol. Polymer Degradation and Stability 98 (2012) 368-376.

27. Wang J. Q., Han Z. D.: The combustion behavior of polyacrylate ester/graphite oxide composites. Polymer for Advance Technology 17 (2006) 335-340. 